\title{
Exigências de metionina + cistina digestível para aves de corte ISA Label criadas em semiconfinamento ${ }^{1}$
}

\section{Dáphinne Cardoso Nagib Nascimento ${ }^{2}$, Nilva Kazue Sakomura ${ }^{3}$, Jefferson Costa de Siqueira $^{2}$, Sandra Regina Freitas Pinheiro ${ }^{2}$, João Batista Kochenborger Fernandes ${ }^{4}$, Renato Luis Furlan ${ }^{5}$}

\author{
1 Projeto financiado pelo CNPq. \\ 2 Pós-graduação em Zootecnia - FCAV - UNESP/Jaboticabal. \\ ${ }^{3}$ Departamento de Zootecnia - FCAV - UNESP/Jaboticabal. \\ ${ }^{4}$ Caunesp - Jaboticabal - SP. \\ ${ }^{5}$ Departamento de Morfologia e Fisiologia Animal - FCAV - UNESP/Jaboticabal.
}

RESUMO - Foram realizados três experimentos para determinação das exigências de metionina+cistina (met+cis) digestível para aves da linhagem ISA Label. As aves foram criadas em semiconfinamento nas fases inicial (1 a 28 dias), crescimento (28 a 56 dias) e final (56 a 84 dias). Em cada experimento, foram utilizadas 480 aves (metade de cada sexo) alojadas em 24 piquetes. O delineamento experimental utilizado foi o inteiramente casualizado, em esquema fatorial $4 \times 2$ (níveis de met+cis e sexos) com três repetições de 20 aves. Os níveis de met+cis digestível avaliados foram: 0,532;0,652;0,772;0,892\% na fase inicial; 0,$515 ; 0,635 ; 0,755 ; 0,875 \%$ na fase de crescimento; e 0,$469 ; 0,589 ; 0,709 ; 0,829 \%$ na fase final. Foram avaliados o desempenho, as características de carcaça, a deposição de proteína e gordura corporal, o peso e o teor de proteína das penas. Na fase inicial, os níveis de met+cis digestível na ração recomendados para machos e fêmeas foram 0,76 e $0,80 \%$, que correspondem a 0,252 e $0,268 \%$ de met+cis por Mcal de energia metabolizável da ração, respectivamente. Para aves ISA Label na fase de crescimento, recomenda-se $0,716 \%$ de met+cis digestível na ração, independentemente do sexo, que corresponde a $0,235 \%$ de met+cis por Mcal de EM da ração. Na fase final, recomendam-se níveis de met+cis digestível de 0,756 e 0,597\%, que correspondem a 0,244 e $0,193 \%$ de met+cis por Mcal de energia metabolizável na ração para machos e fêmeas, respectivamente.

Palavras-chave: aminoácidos sulfurados, aves de pescoço pelado, frango caipira

\section{Digestible methionine + cystine requirements of ISA Label broilers reared in free-range system}

\begin{abstract}
Three assays were carried out to determine the digestible methionine+cystine (Met+Cys) requirement for ISA Label broilers from both sexes. The birds were reared in free range system on starting phase ( 1 to 28 days), growing phase ( 28 to 56 days) and finishing phase (56 to 84 days). Four hundred and eighty birds were distributed into 24 pens, each one composed of shelter $\left(3.13 \mathrm{~m}^{2}\right)$ and pasture $\left(72.87 \mathrm{~m}^{2}\right)$. The experimental design was completely randomized with eight treatments as factorial arrangement (four Met+Cys levels and two sexes) with three replicates of 20 birds. The digestible Met+Cys levels were $0.532 ; 0.652 ; 0.772 ; 0.892 \%$ for starting phase; $0.515 ; 0.635 ; 0.755 ; 0.875 \%$ for growing phase and $0.469 ; 0.589 ; 0.709 ; 0.829 \%$ for finishing phase. The analyzed parameters were performance, carcass yield, body protein and fat deposition, weight and protein concentration in feathers. In the starting phase, the digestible Met+Cys level estimated for males was 0.765 and $0.803 \%$ for females, corresponding to 0.252 and $0.268 \%$ of Met+Cys/Mcal of ME, respectively. For the growing phase, the digestible Met+Cys level estimated was $0.716 \%$ for both sexes, corresponding to $0.235 \%$ of Met+Cys/Mcal of ME. For the finishing phase, the Met+Cys levels were 0.756 and $0.597 \%$ for males and females, corresponding to 0.244 and $0.193 \%$ of Met+Cys/Mcal of ME respectively.
\end{abstract}

Key Words: broilers, naked-neck birds, sulphurous amino acids

\section{Introdução}

As atividades agropecuárias, de modo geral, permitem que os produtores trabalhem com margens de lucro bastante reduzidas em comparação às atividades de outros setores produtivos, exigindo máxima eficiência do ponto de vista gerencial.

A produção de frangos de corte de crescimento lento em sistemas alternativos de criação tem atraído novos produtores, não apenas por demandar baixos investimentos 
com a implantação, mas também por possibilitar maiores preços de venda do produto final, o que favorece a rentabilidade da atividade.

$\mathrm{Na}$ avicultura, o custo com a alimentação representa aproximadamente $70 \%$ do custo de produção, por isso, são necessárias dietas balanceadas de acordo com as necessidades das aves e que proporcionem máxima eficiência de utilização da dieta e ótimo desempenho dos animais.

Entre os nutrientes essenciais que influenciam diretamente o desempenho das aves, destaca-se a metionina, primeiro aminoácido limitante para esses animais quando são utilizadas dietas à base de milho e soja. Além disso, a metionina desempenha várias funções no organismo das aves e tem efeito no sistema imune (Kalinowski et al., 2003), na deposição de proteína (Hruby, 1998), no metabolismo de lipídeos (Jensen, 1990) e no metabolismo energético (Boomgardt \& Baker, 1973). Outras funções da metionina incluem a doação de radicais metil, precursora da biossíntese da cisteína, que, ligada aos pares por uma ponte dissulfeto, forma a cistina, o que justifica o fato de as recomendações nutricionais serem expressas como metionina+cistina. A conversão de metionina em cisteína ocorre pelo mecanismo de trans-sulfuração, um processo irreversível, por isso, é extremamente importante o fornecimento de quantidades adequadas de metionina nas dietas (Rademacher, 2001).

De acordo com Kalinowski et al. (2003a; 2003b), os níveis de met+cis das rações podem influenciar o empenamento das aves, assim, aves de linhagens de empenamento rápido exigem níveis de met+cis superiores aos requeridos por aves de linhagem de empenamento lento. Considerando que as aves da linhagem ISA Label possuem desenvolvimento tardio em comparação a aves de linhagens convencionais (Santos et al., 2005), e considerando ainda que as aves dessa linhagem possuem características diferenciadas de empenamento, é possível que respondam aos níveis de met+cis da dieta de maneira diferenciada daquela observada para linhagens comerciais de frangos de corte.

Este estudo foi realizado com o objetivo de estimar as exigências de metionina+cistina digestível para aves da linhagem ISA Label de ambos os sexos criadas em sistema de semiconfinamento nas fases inicial (1 a 28 dias), crescimento (28 a 56 dias) e final ( 56 a 84 dias).

\section{Material e Métodos}

Foram realizados três experimentos no Setor de Avicultura do Departamento de Zootecnia da Faculdade de Ciências Agrárias e Veterinárias - FCAV/UNESP,
Jaboticabal, São Paulo, no período de 10 de julho a 2 de outubro de 2006, para determinação das exigências de met+cis digestível para aves da linhagem ISA Label, de ambos os sexos, em sistema de semiconfinamento nas fases inicial (1 a 28 dias), crescimento (28 a 56 dias) e final (56 a 84 dias).

Em cada fase, foram utilizadas 480 aves (metade de cada sexo) distribuídas nas instalações experimentais, constituídas de 24 piquetes contendo abrigo com área de $3,13 \mathrm{~m}^{2} \mathrm{e}$ área de pastejo de $72,87 \mathrm{~m}^{2}$ contendo, predominantemente, gramíneas do gênero Paspalum.

$O$ delineamento experimental utilizado foi o inteiramente casualizado, em esquema fatorial $4 \times 2$ (níveis de met+cis digestível $\times$ sexo), totalizando oito tratamentos, cada um com três repetições de 20 aves por unidade experimental.

$\mathrm{Na}$ fase inicial, as aves alojadas com 1 dia de idade foram limitadas ao abrigo até o $21^{\circ}$ dia, quando passaram a ter acesso à área de pastejo. As aves utilizadas nas fases de crescimento e final foram criadas em galpão convencional até o $28^{\circ}$ e $56^{\circ}$ dia, respectivamente, e receberam rações formuladas para atender às exigências em cada fase (NRC, 1994).

As rações basais para cada fase foram à base de milho e farelo de soja, de acordo com as recomendações do NRC (1994), exceto em aminoácidos. Os níveis de aminoácidos foram estabelecidos com base nas relações ideais propostas por Rostagno (2005), tomando-se como referência os níveis de lisina digestível estabelecidos em estudos realizados para determinação das exigências de lisina digestível de aves ISA Label (Nascimento, 2007).

As rações basais deficientes em met+cis (Tabela 1) foram suplementadas com DL-metionina em substituição ao ácido L-glutâmico e ao amido, resultando em rações isoenergéticas e isonitrogênicas contendo 0,$532 ; 0,652$; 0,$772 ; 0,892 \%$ de met+cis digestível para a fase inicial, 0,$515 ; 0,635 ; 0,755 ; 0,875 \%$ para a fase de crescimento e 0,$469 ; 0,589 ; 0,709 ; 0,829 \%$ para a fase final.

As características de desempenho avaliadas em cada fase foram o ganho de peso (g/ave), o consumo de ração (g/ave), o consumo de met+cis (g/ave) e a conversão alimentar $(\mathrm{g} / \mathrm{g})$. No $84^{\circ}$ dia, três aves de cada parcela ( 72 no total), com peso corporal próximo ao da média da parcela $( \pm 10 \%)$, foram submetidas a jejum alimentar de 12 horas e abatidas para avaliação dos rendimentos de carcaça e cortes nobres. Foram determinadas as deposições de proteína e gordura corporal, por meio de abates comparativos no início (grupos referência) e final de cada experimento. Os grupos referência foram constituídos por aves de ambos os sexos, com peso $\pm 10 \%$ do peso médio inicial, totalizando 
Tabela 1 - Composição das dietas basais utilizadas em cada fase de criação

\begin{tabular}{|c|c|c|c|}
\hline \multirow[t]{2}{*}{ Ingrediente $(\%)$} & \multicolumn{3}{|c|}{ Fase } \\
\hline & Inicial & Crescimento & Final \\
\hline Milho & 65,112 & 68,818 & 75,298 \\
\hline Farelo de soja & 28,744 & 25,894 & 19,866 \\
\hline Óleo de soja & 1,203 & 1,203 & 0,761 \\
\hline Calcário & 1,127 & 1,228 & 1,197 \\
\hline Fosfato bicálcico & 1,709 & 1,288 & 1,103 \\
\hline Sal comum & 0,416 & 0,314 & 0,254 \\
\hline Suplemento mineral ${ }^{1}$ & 0,100 & 0,100 & 0,100 \\
\hline Suplemento vitamínico ${ }^{2}$ & 0,100 & 0,100 & 0,100 \\
\hline DL-metionina & 0,000 & 0,000 & 0,000 \\
\hline L-lisina $\mathrm{HCl}$ & 0,218 & 0,257 & 0,121 \\
\hline L-treonina & 0,051 & 0,063 & 0,000 \\
\hline L-valina & 0,000 & 0,035 & 0,000 \\
\hline Ácido L-glutâmico & 1,000 & 0,500 & 1,000 \\
\hline Amido & 0,150 & 0,150 & 0,150 \\
\hline Cloreto de colina $70 \%$ & 0,070 & 0,050 & 0,050 \\
\hline Total & 100,000 & 100,000 & 100,000 \\
\hline \multicolumn{4}{|l|}{ Composição calculada } \\
\hline Proteína bruta (\%) & 19,293 & 18,000 & 16,031 \\
\hline Energia metabolizável (kcal/kg) & 3000 & 3050 & 3100 \\
\hline Cálcio $(\%)$ & 0,940 & 0,870 & 0,800 \\
\hline Fósforo disponível (\%) & 0,420 & 0,340 & 0,300 \\
\hline Sódio (\%) & 0,190 & 0,150 & 0,120 \\
\hline Met+cis digestível (\%) & 0,532 & 0,515 & 0,469 \\
\hline Metionina digestível (\%) & 0,207 & 0,260 & 0,236 \\
\hline Lisina digestível (\%) & 1,041 & 1,006 & 0,760 \\
\hline Treonina digestível (\%) & 0,673 & 0,654 & 0,515 \\
\hline Valina digestível (\%) & 0,786 & 0,755 & 0,647 \\
\hline
\end{tabular}

${ }^{1} \mathrm{Mn}-75.000 \mathrm{mg} ; \mathrm{Fe}-50.000 \mathrm{mg}$; Zn - $70.000 \mathrm{mg} ; \mathrm{Cu}-8.500 \mathrm{mg}$; Co - $200 \mathrm{mg}$; I - $1.500 \mathrm{mg}$; veículo q.s.p. $-1.000 \mathrm{~g}$.

${ }^{2}$ Vit. A - $12.000 .000 \mathrm{UI}$; vit. $\mathrm{D}_{3}-2.200 .000 \mathrm{UI}$; vit. E - $30 \mathrm{~g}$; vit. $\mathrm{B}_{1}-2,2 \mathrm{~g}$; vit. $\mathrm{B}_{2}-6 \mathrm{~g}$, vit. $\mathrm{B}_{6}-3,3 \mathrm{~g}$; vit. $\mathrm{B}_{12}-0,016 \mathrm{mcg}$; ácido pantotênico - $13 \mathrm{~g}$; vit. $\mathrm{K}_{-3}$ $2,5 \mathrm{~g}$; ácido fólico - $1 \mathrm{~g}$; Se - $250 \mathrm{mg}$; antioxidante - $100.000 \mathrm{mg}$; veículo q.s.p.$1.000 \mathrm{~g}$.

nove aves (três repetições de três aves) para cada sexo em cada um dos experimentos. No término de cada experimento, três aves de cada parcela com peso $\pm 10 \%$ do peso médio foram selecionadas, totalizando 72 aves. Após jejum alimentar de 24 horas, para o esvaziamento completo do trato digestório, as aves foram pesadas, abatidas por deslocamento cervical e, após a obtenção de uma amostra representativa das penas de cada ave, foram completamente depenadas e pesadas novamente. Pela diferença entre o peso em jejum $(\mathrm{g})$ e o peso das aves depenadas $(\mathrm{g})$, obteve-se o peso absoluto das penas (g). O peso relativo das penas (\%) foi obtido pela razão entre o peso absoluto das penas e o peso das aves em jejum multiplicado por 100.

As aves depenadas e as respectivas amostras de penas foram devidamente identificadas e acondicionadas em freezer $\left(-8^{\circ} \mathrm{C}\right)$, sendo posteriormente processadas para a determinação dos teores de matéria seca, extrato etéreo e proteína bruta de acordo com as metodologias descritas por Silva \& Queiroz (2002).
Os dados de desempenho, das características de carcaça e da composição corporal foram submetidos a análises de variância e de regressão considerando-se os níveis de met+cis digestível da ração como variável independente. As estimativas dos níveis de met+cis foram feitas por meio dos modelos Linear Response Plateau (LRP) e/ou polinomial quadrático. Também foi utilizado o procedimento descrito por Sakomura \& Rostagno (2007), no qual o nível de met+cis foi estimado por meio do primeiro ponto de intersecção da curva quadrática com o platô do modelo LRP. Para calcular as intersecções aplicou-se a fórmula: $X=\left(-\beta_{1} \pm\left(\beta_{1}^{2}-4\left(\beta_{2}\left(\beta_{0}-L\right)\right)\right)^{1 / 2}\right) / 2 \beta_{2}$; em que $X$ são as intersecções da equação quadrática com o platô do LRP, $\beta_{0}, \beta_{1}$ e $\beta_{2}$ são, respectivamente, a constante, o parâmetro linear e o parâmetro quadrático da equação quadrática e L, o valor da variável de interesse estimado pelo platô do LRP. Para aquelas variáveis cujos efeitos dos níveis de met+cis foram detectados pela análise de variância,mas não foi possível ajustar nenhum dos modelos de regressão propostos, utilizou-se o teste Duncan a 5\% de probabilidade para comparar as médias.

As análises estatísticas foram realizadas com o uso do software SAEG 9.0(UFV, 2001).

\section{Resultados e Discussão}

$\mathrm{Na}$ fase inicial (1 a 28 dias), os níveis de met+cis digestível da ração influenciaram todas as características de desempenho avaliadas $(\mathrm{P} \leq 0,05)$, com exceção do consumo de ração (CR), da deposição de gordura corporal (DG) e do peso relativo de penas (PR) (Tabela 2). Da mesma forma, observou-se efeito de sexo para todas as características $(P \leq 0,05)$, exceto para a conversão alimentar (CA) e para a deposição de gordura corporal. De acordo com Kessler et al. (2000), a taxa de deposição de gordura corporal, em diversas idades, é similar entre machos e fêmeas, conseqüentemente, quando há menor crescimento muscular, as fêmeas se tornam mais gordas. Considerando que, na fase inicial da vida das aves, a diferença nas taxas de crescimento de machos e fêmeas é pequena, espera-se que diferenças de deposição de gordura corporal entre os sexos ocorram apenas em idades mais avançadas.

Foi observado efeito da interação $(\mathrm{P} \leq 0,05)$ níveis de met+cis da ração $\times$ sexo para o ganho de peso (GP), evidenciando que as respostas aos níveis de met+cis dos machos diferem das respostas de fêmeas.

O consumo de met+cis digestível (CMet) aumentou de forma linear crescente com os níveis de met+cis da ração (Tabela 3). Como não houve efeito dos níveis de met+cis 
Tabela 2 - Desempenho de aves ISA Label alimentadas com rações com diversos níveis de met+cis digestível no período de 1 a 28 dias de idade

\begin{tabular}{|c|c|c|c|c|c|c|c|c|c|c|}
\hline \multirow[t]{2}{*}{ Variável } & \multirow[t]{2}{*}{ Sexo } & \multicolumn{4}{|c|}{ Nível de met+cis digestível } & \multirow[t]{2}{*}{ Geral } & \multirow[t]{2}{*}{$\mathrm{CV}(\%)$} & \multicolumn{3}{|c|}{ Probabilidade de F } \\
\hline & & 0,532 & 0,652 & 0,772 & 0,892 & & & Met+cis & Sexo & $\begin{array}{c}\text { Met }+ \text { cis } \\
\times \text { sexo }\end{array}$ \\
\hline Consumo de ração (g) & $\begin{array}{c}\text { Macho } \\
\text { Fêmea } \\
\text { Geral }\end{array}$ & $\begin{array}{l}1.085,83 \\
1.006,02 \\
1.045,92\end{array}$ & $\begin{array}{c}1.087,50 \\
963,64 \\
1.025,57\end{array}$ & $\begin{array}{l}1.079,17 \\
1.016,42 \\
1.047,80\end{array}$ & $\begin{array}{l}1.057,50 \\
1.053,13 \\
1.055,31\end{array}$ & $\begin{array}{l}1.077,50 \\
1.009,80\end{array}$ & 5,15 & NS & $\leq 0,01$ & NS \\
\hline $\begin{array}{l}\text { Consumo de metionina+ } \\
\text { cistina digestível }(\mathrm{g})\end{array}$ & $\begin{array}{c}\text { Macho } \\
\text { Fêmea } \\
\text { Geral }\end{array}$ & $\begin{array}{l}5,80 \\
5,37 \\
5,59\end{array}$ & $\begin{array}{l}7,09 \\
6,28 \\
6,69\end{array}$ & $\begin{array}{l}8,33 \\
7,85 \\
8,09\end{array}$ & $\begin{array}{l}9,43 \\
9,39 \\
9,41\end{array}$ & $\begin{array}{l}7,66 \\
7,22\end{array}$ & 5,38 & $\leq 0,01$ & $\leq 0,05$ & NS \\
\hline Ganho de peso (g) & $\begin{array}{c}\text { Macho } \\
\text { Fêmea } \\
\text { Geral }\end{array}$ & $\begin{array}{l}513,97 \\
471,66 \\
492,81\end{array}$ & $\begin{array}{l}574,64 \\
492,64 \\
533,64\end{array}$ & $\begin{array}{l}576,48 \\
542,10 \\
559,29\end{array}$ & $\begin{array}{l}565,65 \\
546,80 \\
556,22\end{array}$ & $\begin{array}{l}558,52 \\
513,30\end{array}$ & 3,41 & $\leq 0,01$ & $\leq 0,01$ & $\leq 0,05$ \\
\hline $\begin{array}{l}\text { Conversão } \\
\text { alimentar (g/g) }\end{array}$ & $\begin{array}{c}\text { Macho } \\
\text { Fêmea } \\
\text { Geral }\end{array}$ & $\begin{array}{l}2,11 \\
2,13 \\
2,12\end{array}$ & $\begin{array}{l}1,89 \\
1,96 \\
1,92\end{array}$ & $\begin{array}{l}1,87 \\
1,87 \\
1,87\end{array}$ & $\begin{array}{l}1,87 \\
1,93 \\
1,90\end{array}$ & $\begin{array}{l}1,94 \\
1,97\end{array}$ & 3,04 & $\leq 0,01$ & NS & NS \\
\hline $\begin{array}{l}\text { Deposição de } \\
\text { proteína corporal }(\mathrm{g})\end{array}$ & $\begin{array}{c}\text { Macho } \\
\text { Fêmea } \\
\text { Geral }\end{array}$ & $\begin{array}{c}100,21 \\
89,78 \\
94,99\end{array}$ & $\begin{array}{l}113,07 \\
100,80 \\
106,94\end{array}$ & $\begin{array}{l}117,65 \\
116,55 \\
117,10\end{array}$ & $\begin{array}{l}119,63 \\
113,81 \\
116,72\end{array}$ & $\begin{array}{l}112,64 \\
105,23\end{array}$ & 6,32 & $\leq 0,01$ & $\leq 0,05$ & NS \\
\hline $\begin{array}{l}\text { Deposição de } \\
\text { gordura corporal }(\mathrm{g})\end{array}$ & $\begin{array}{c}\text { Macho } \\
\text { Fêmea } \\
\text { Geral }\end{array}$ & $\begin{array}{l}42,59 \\
39,05 \\
40,82\end{array}$ & $\begin{array}{l}38,10 \\
34,41 \\
36,25\end{array}$ & $\begin{array}{l}37,58 \\
33,80 \\
35,69\end{array}$ & $\begin{array}{l}34,92 \\
42,40 \\
38,66\end{array}$ & $\begin{array}{l}38,29 \\
37,42\end{array}$ & 12,24 & NS & NS & NS \\
\hline $\begin{array}{l}\text { Peso relativo } \\
\text { das penas }(\%)\end{array}$ & $\begin{array}{c}\text { Macho } \\
\text { Fêmea } \\
\text { Geral }\end{array}$ & $\begin{array}{l}6,06 \\
5,98 \\
6,02\end{array}$ & $\begin{array}{l}6,39 \\
6,55 \\
6,47\end{array}$ & $\begin{array}{l}5,99 \\
6,74 \\
6,37\end{array}$ & $\begin{array}{l}6,15 \\
7,06 \\
6,61\end{array}$ & $\begin{array}{l}6,15 \\
6,58\end{array}$ & 6,39 & NS & $\leq 0,05$ & NS \\
\hline $\begin{array}{l}\text { Teor de proteína } \\
\text { das penas }(\%)\end{array}$ & $\begin{array}{c}\text { Macho } \\
\text { Fêmea } \\
\text { Geral }\end{array}$ & $\begin{array}{c}85,56 \\
88,80 \\
87,18 b\end{array}$ & $\begin{array}{l}87,14 \\
87,62 \\
7,38 b\end{array}$ & $\begin{array}{c}87,89 \\
91,56 \\
89,73 \mathrm{a}\end{array}$ & $\begin{array}{c}87,56 \\
89,40 \\
88,48 \mathrm{ab}\end{array}$ & $\begin{array}{l}87,03 \\
89,35\end{array}$ & 1,47 & $\leq 0,05$ & $\leq 0,01$ & NS \\
\hline
\end{tabular}

$\mathrm{CV}=$ coeficiente de variação; $\mathrm{NS}$ = não-significativo $(\mathrm{P}>0,05)$.

Médias seguidas de letras iguais nas linhas não diferem $(P>0,05)$ entre si pelo teste Duncan.

sobre o consumo de ração, é provável que o aumento no consumo de metionina+cistina seja responsável pela melhora no ganho de peso das aves, especialmente nas fêmeas, que alcançaram o platô de resposta com níveis mais elevados de met+cis em comparação aos machos.

As respostas de ganho de peso dos machos foram ajustadas pelos modelos polinomial quadrático e LRP (Tabela 3), estimando-se os níveis de met+cis digestível de 0,765 e $0,645 \%$, correspondentes aos consumos de met+cis de 8,01 e 6,71 g/ave, respectivamente (Tabela 3). Outra forma de estimar as exigências nutricionais em experimentos dose-resposta é a combinação do modelo quadrático com o LRP, determinando-se a primeira intersecção da equação quadrática com o platô de LRP (Sakomura \& Rostagno, 2007). O nível estimado pela combinação dos modelos foi $0,665 \%$ de met+cis digestível na ração, intermediário àqueles obtidos com o LRP e o modelo quadrático. Esse nível correspondeu ao consumo de met+cis de $6,93 \mathrm{~g} /$ ave durante o período de 1 a 28 dias, equivalente a $0,222 \%$ de met+cis digestível/Mcal de EM da ração.
Nas fêmeas, observou-se comportamento linear crescente do ganho de peso aos níveis de met+cis da ração, o que tornou possível estimar as exigências com o uso do modelo LRP. Assim, estimou-se o nível de 0,803\% de met+cis, correspondente a consumo de metionina de 8,42 g/ ave ou $0,268 \%$ de met+cis digestível/Mcal de EM da ração, para fêmeas ISA Label durante o período de 1 a 28 dias.

Com base nas máximas respostas estimadas com o modelo quadrático para os machos e o LRP para as fêmeas, estimou-se a exigência de 14,34 g de met+cis digestível por $\mathrm{kg}$ de ganho de peso para os machos, enquanto as fêmeas exigiram $16,40 \mathrm{~g}$ por $\mathrm{kg}$ de ganho de peso, evidenciando que as fêmeas são menos eficientes em utilizar met+cis para ganho de peso. Neste estudo o maior valor do peso relativo de penas observado para as fêmeas aos 28 dias comprova empenamento mais acelerado que o dos machos, conforme relatado por Pesti et al. (1996). De acordo com Gous et al. (1999), a proteína das penas tem alta concentração de cistina (70 g/kg PB), diferindo bastante da composição protéica do resto do corpo. Assim, pode-se inferir que as fêmeas direcionaram maior proporção de met+cis 
Tabela 3 - Equações ajustadas para as características de desempenho, coeficientes de determinação $\left(\mathrm{R}^{2}\right)$ e níveis de met+cis estimados (NMCE) com o uso de diversas equações

\begin{tabular}{|c|c|c|c|}
\hline Modelo & Variável/Equação & $\operatorname{NMCE}(\%)$ & $\mathrm{R}^{2}$ \\
\hline Linear & $\begin{array}{l}\text { Consumo met+cis }(\mathrm{g})-\text { Machos e Fêmeas } \\
\text { Consumo de met+cis }=-0,248+10,795 \text { MC }\end{array}$ & - & 0,99 \\
\hline \multicolumn{4}{|c|}{ Ganho de peso (g) - Machos } \\
\hline LRP & $\mathrm{GP}=239,42+514,13 \mathrm{MC}(\mathrm{p} / \mathrm{MC}<0,645 \%)$ & 0,645 & 1,00 \\
\hline Quadrático & $\mathrm{GP}=-153,59+1927,23 \mathrm{MC}-1259,57 \mathrm{MC} 2$ & 0,765 & 0,96 \\
\hline Quadrático+LRP & $\begin{array}{c}\left(-1927,23+\left(1927,23^{2}-4 \times(-1259,57 \times(-153,59-571,03))\right)^{1 / 2}\right) /(2 \times-1259,57)=0,665 \\
\text { Ganho de peso }(\mathrm{g})-\text { Fêmeas }\end{array}$ & 0,665 & - \\
\hline LRP & $\mathrm{GP}=308,77+296,27 \mathrm{MC}(\mathrm{p} / \mathrm{MC}<0,803 \%)$ & 0,803 & 0,95 \\
\hline Linear & $\mathrm{GP}=349,29+230,19 \mathrm{MC}$ & - & 0,92 \\
\hline \multicolumn{4}{|c|}{ Conversão alimentar (g/g) - Machos e Fêmeas } \\
\hline LRP & $\mathrm{CA}=3,023-1,685 \mathrm{MC}(\mathrm{p} / \mathrm{MC}<0,675 \%)$ & 0,675 & 1,00 \\
\hline Quadrático & $\mathrm{CA}=4,329-6,252 \mathrm{MC}+3,958 \mathrm{MC}^{2}$ & 0,789 & 0,99 \\
\hline Quadrático+LRP & $\left(6,252+\left(6,252^{2}-4 \times(3,958 \times(4,329-1,885))\right)^{1 / 2}\right) /(2 \times 3,958)=0,710$ & 0,710 & - \\
\hline \multicolumn{4}{|c|}{ Deposição de proteína corporal $(\mathrm{g})$ - Machos e Fêmeas } \\
\hline LRP & $\mathrm{DP}=40,962+101,188 \mathrm{MC}(\mathrm{p} / \mathrm{MC}<0,751 \%)$ & 0,751 & 1,00 \\
\hline Quadrático & $\mathrm{DP}=-43,486+375,540 \mathrm{MC}-219,126 \mathrm{MC}^{2}$ & 0,856 & 0,99 \\
\hline Quadrático+LRP & $\left(-375,540+\left(375,540^{2}-4 \times(-219,126 \times(-43,486-116,91))\right)^{1 / 2}\right) /(2 \times-219,126)=0,809$ & 0,809 & - \\
\hline
\end{tabular}

NMCE = Nível de met+cis estimado.

consumida para o empenamento em comparação aos machos, o que explica a menor eficiência de utilização da met+cis para ganho de peso.

Considerando a conversão alimentar, foi possível ajustar os modelos polinomial quadrático e LRP e estimar os níveis de 0,789 e $0,675 \%$ de met+cis digestível da ração, para ambos os sexos, correspondentes a consumos de met+cis de 8,26e 7,04 g/ave, respectivamente. A primeira intersecção da curva quadrática com o platô do LRP resultou na estimativa de $0,710 \%$ de met+cis digestível na ração, correspondente a consumo de met+cis de 7,42 g/ave, durante o período de 1 a 28 dias de idade.

A deposição de proteína corporal (DP) foi influenciada pelos níveis de met+cis da ração e ajustou-se aos modelos LRP e quadrático. Com o uso do LRP, foi estimado o nível de $0,751 \%$ de met+cis digestível na ração, equivalente ao consumo de met+cis de $7,85 \mathrm{~g}$ /ave. Pelo modelo quadrático, o nível de met+cis digestível foi estimado em $0,856 \%$ $(8,99 \mathrm{~g} / \mathrm{ave})$. A primeira intersecção da quadrática com o platô do LRP resultou na estimativa de $0,809 \%$ de met+cis. Esta estimativa se aproxima daquela obtida por Oliveira Neto et al. (2005), que estimaram 0,818\% de met+cis digestível como o nível adequado para aumentar a deposição protéica em frangos de corte de 1 a 21 dias de idade. Conforme descrito por Kyriazakis et al. (1994), citados por Oliveira Neto et al. (2005), a deposição de proteína, por agregar maior quantidade de água que a deposição de gordura, resulta em maior ganho de peso e eficiência de ganho. Os resultados deste estudo comprovam que os machos depositaram 7,41 g de proteína corporal a mais que as fêmeas no período de 1 a 28 dias de idade, resultando em maior ganho de peso e menor exigência de met+cis por kg de ganho de peso $(14,34 \mathrm{~g})$ em relação às fêmeas $(16,40 \mathrm{~g})$, o que confirma os relatos de Kyriazakis et al. (1994).

Pela análise de variância (Tabela 2) detectou-se efeito $(\mathrm{P} \leq 0,05)$ dos níveis de met+cis da ração sobre o teor de proteína das penas, contudo, os modelos LRP e quadrático não se ajustaram ao comportamento dos dados, por isso, utilizou-se nesse caso o teste Duncan para comparar as médias dos níveis de met+cis na ração. $O$ peso de penas obtido com a ração contendo $0,772 \%$ met+cis digestível foi superior aos obtidos com as rações com menores concentrações de met+cis $(0,532$ e $0,652 \%)$.

As respostas de conversão alimentar e deposição de proteína aos níveis de met+cis da ração foram semelhantes entre os sexos e resultaram nas mesmas estimativas para machos e fêmeas, entretanto, as respostas de ganho de peso variaram, o que evidencia a necessidade de recomendações específicas para machos e fêmeas. Para os machos, o nível de met+cis digestível de $0,765 \%$, estimado com o uso da equação quadrática, correspondeu à relação met+cis: lisina de 73\%, bastante próxima às relações de 72 e $71 \%$ recomendadas por Han \& Baker (1994) e Rostagno et al. (2005), respectivamente, para frangos de corte de 1 a 21 dias. Para as fêmeas o nível de $0,803 \%$, estimado com o uso do LRP, correspondeu à relação met+cis: lisina de $77 \%$. Estes resultados se assemelham aos obtidos por Albino et al. (1999), que observaram diferenças entre os sexos e recomendaram níveis de met+cis de $0,886 \%$ para machos e 0,896\% para fêmeas da linhagem Hubbard, correspondentes às relações met+cis: lisina de $74 \%$ para machos e $75 \%$ para fêmeas no período de 1 a 21 dias. 
Observou-se efeito $(\mathrm{P} \leq 0,05)$ do sexo para todas as variáveis avaliadas no período de 28 a 56 dias de idade (Tabela 4), exceto para o peso relativo de penas, que foi semelhante entre machos e fêmeas. Tomando-se como referência os resultados de peso relativo de penas aos 28 dias, pode-se inferir que, apesar de os machos apresentarem empenamento mais tardio, em ambos os sexos, o empenamento encerrou no período entre 28 e 56 dias de idade. Os níveis de met+cis da ração influenciaram todas as variáveis $(\mathrm{P} \leq 0,05)$, com exceção da deposição de proteína, do peso relativo das penas e do teor de proteína das penas. Houve interação $(\mathrm{P} \leq 0,01)$ entre os níveis de met+cis da ração e o sexo somente para o consumo de met+cis.

O consumo de ração foi influenciado pelos níveis de met+cis, entretanto, os modelos de regressão propostos não se ajustaram adequadamente aos dados e utilizou-se neste caso o teste de Duncan para comparar as médias dos níveis de met+cis. As aves que receberam a dieta contendo $0,635 \%$ de met+cis apresentaram consumo de ração inferior ao das aves que receberam a dieta basal $(0,515 \%)$. Considerando que a deficiência de met+cis da dieta basal foi mais severa, o aumento do consumo de ração pode estar relacionado à capacidade das aves de compensar o consumo marginal de aminoácidos e aumentar o consumo de ração para reduzir as deficiências (Schutte \& Pack, 1995).

Os resultados da análise de variância (Tabela 4) evidenciaram o efeito dos níveis de met+cis sobre o ganho de peso das aves, contudo, os modelos de regressão propostos não se ajustaram ao comportamento dos dados, por isso, utilizou-se o teste Duncan para comparar as médias dos tratamentos. As dietas contendo 0,755 e $0,875 \%$ de met+cis proporcionaram ganhos de peso semelhantes e superiores aos obtidos com as dietas contendo $0,515 \mathrm{e}$ $0,635 \%$ de met+cis, que também não diferiram entre si.

Considerando a conversão alimentar, a ausência de interação entre os fatores estudados indicou que as respostas de machos e de fêmeas foram semelhantes, o que justifica o ajuste de equações utilizando-se os dados provenientes de ambos os sexos. Os modelos polinomial quadrático e LRP se ajustaram adequadamente aos dados de conversão alimentar (Tabela 5); foram estimados os níveis de 0,784 e

Tabela 4 - Desempenho de aves ISA Label alimentadas com rações com diversos níveis de met+cis digestível no período de 28 aos 56 dias de idade

\begin{tabular}{|c|c|c|c|c|c|c|c|c|c|c|}
\hline \multirow[t]{2}{*}{ Variável } & \multirow[t]{2}{*}{ Sexo } & \multicolumn{4}{|c|}{ Nível de met+cis digestível } & \multirow[t]{2}{*}{ Geral } & \multirow[t]{2}{*}{$\mathrm{CV}(\%)$} & \multicolumn{3}{|c|}{ Probabilidade de F } \\
\hline & & 0,515 & 0,635 & 0,755 & 0,875 & & & Met+cis & Sexo & $\begin{array}{c}\text { Met+cis } \\
\times \text { sexo }\end{array}$ \\
\hline \multirow{3}{*}{ Consumo de ração (g) } & Macho & $2.924,38$ & $2.851,83$ & $2.916,67$ & $2.907,50$ & $2.900,10$ & 1,76 & $\leq 0,05$ & $\leq 0,01$ & NS \\
\hline & Fêmea & $2.399,03$ & $2.303,00$ & $2.324,69$ & $2.323,00$ & $2.337,43$ & & & & \\
\hline & Geral & $2.661,71 \mathrm{a}$ & $2.577,42 b$ & $2.620,68 \mathrm{ab}$ & $2.615,25 \mathrm{ab}$ & & & & & \\
\hline \multirow{3}{*}{$\begin{array}{l}\text { Consumo de metionina+ } \\
\text { cistina digestível }(\mathrm{g})\end{array}$} & Macho & 15,06 & 18,11 & 22,02 & 25,44 & 20,16 & 1,82 & $\leq 0,01$ & $\leq 0,01$ & $\leq 0,01$ \\
\hline & Fêmea & 12,36 & 14,62 & 17,55 & 20,33 & 16,21 & & & & \\
\hline & Geral & 13,71 & 16,37 & 19,79 & 22,88 & & & & & \\
\hline \multirow{3}{*}{ Ganho de peso $(\mathrm{g})$} & Macho & $1.141,93$ & $1.132,33$ & $1.184,17$ & $1.178,33$ & $1.159,20$ & 1,83 & $\leq 0,05$ & $\leq 0,01$ & NS \\
\hline & Fêmea & 875,69 & 880,26 & 893,61 & 886,04 & 883,90 & & & & \\
\hline & Geral & $1.008,81 \mathrm{~b}$ & $1.006,30 \mathrm{~b}$ & $1.038,89 \mathrm{a}$ & $1.032,19 \mathrm{a}$ & & & & & \\
\hline \multirow{3}{*}{ Conversão alimentar (g/g) } & Macho & 2,561 & 2,519 & 2,463 & 2,468 & 2,503 & 1,61 & $\leq 0,01$ & $\leq 0,01$ & NS \\
\hline & Fêmea & 2,739 & 2,617 & 2,601 & 2,622 & 2,645 & & & & \\
\hline & Geral & 2,650 & 2,568 & 2,532 & 2,545 & & & & & \\
\hline \multirow{3}{*}{ Deposição de proteína (g) } & Macho & 213,18 & 215,86 & 243,56 & 220,93 & 223,38 & 8,11 & NS & $\leq 0,01$ & NS \\
\hline & Fêmea & 165,54 & 172,25 & 174,80 & 144,93 & 164,38 & & & & \\
\hline & Geral & 189,36 & 194,06 & 209,18 & 182,93 & & & & & \\
\hline \multirow{3}{*}{ Deposição de gordura (g) } & Macho & 141,61 & 141,04 & 119,97 & 175,83 & 144,61 & 11,18 & $\leq 0,01$ & $\leq 0,01$ & NS \\
\hline & Fêmea & 105,65 & 104,11 & 103,97 & 113,67 & 106,85 & & & & \\
\hline & Geral & $123,63 b$ & $122,58 \mathrm{~b}$ & $111,97 \mathrm{~b}$ & $144,75 \mathrm{a}$ & & & & & \\
\hline \multirow{3}{*}{$\begin{array}{l}\text { Peso relativo } \\
\text { das penas }(\%)\end{array}$} & Macho & 4,30 & 5,12 & 5,12 & 5,48 & 5,00 & 14,13 & NS & NS & NS \\
\hline & Fêmea & 5,25 & 4,52 & 5,99 & 5,28 & 5,26 & & & & \\
\hline & Geral & 4,76 & 4,82 & 5,56 & 5,38 & & & & & \\
\hline \multirow{3}{*}{$\begin{array}{l}\text { Teor de proteína } \\
\text { das penas }(\%)\end{array}$} & Macho & 86,96 & 85,45 & 87,21 & 88,20 & 86,96 & 1,28 & NS & $\leq 0,05$ & NS \\
\hline & Fêmea & 88,36 & 87,30 & 89,28 & 86,81 & 87,94 & & & & \\
\hline & Geral & 87,66 & 86,38 & 88,25 & 87,51 & & & & & \\
\hline
\end{tabular}

$\mathrm{CV}=$ coeficiente de variação; NS = não-significativo $(\mathrm{P}>0,05)$.

Médias seguidas de letras iguais nas linhas não diferem $(P>0,05)$ entre si pelo teste Duncan. 
Tabela 5 - Equações ajustadas para o consumo de met+cis e a conversão alimentar em cada nível de met+cis digestível, coeficientes de determinação $\left(\mathrm{R}^{2}\right)$ e níveis de met+cis estimados com o uso do diferentes modelos de regressão

\begin{tabular}{|c|c|c|c|}
\hline Modelo & Variável/Equação & NMCE $(\%)$ & $\mathrm{R}^{2}$ \\
\hline $\begin{array}{l}\text { Linear } \\
\text { Linear }\end{array}$ & $\begin{array}{l}\text { Consumo de met }+ \text { cis }(\mathrm{g})-\text { Machos } \\
\text { CMet }=-0,143+29,209 \text { MC } \\
\text { Consumo de met+cis }(\mathrm{g})-\text { Fêmeas } \\
\text { CMet }=0,669+22,367 \text { MC }\end{array}$ & - & $\begin{array}{l}0,99 \\
0,99\end{array}$ \\
\hline $\begin{array}{l}\text { LRP } \\
\text { Quadrático } \\
\text { Quadrático + LRP }\end{array}$ & $\begin{array}{c}\text { Conversão alimentar }(\mathrm{g} / \mathrm{g})-\text { Machos e Fêmeas } \\
\text { CA }=3,005564-0,68948 \mathrm{MC}(\mathrm{p} / \mathrm{MC}<0,677 \%) \\
\mathrm{CA}=3,54716-2,59294 \mathrm{MC}+1,65419 \mathrm{MC} 2 \\
\left(2,5929-\left(2,5929^{2}-4 \times(1,65419 \times(3,54716-2,5386))\right)^{1 / 2}\right) /(2 \times 1,65419)=0,716\end{array}$ & $\begin{array}{l}0,677 \\
0,784 \\
0,716\end{array}$ & $\begin{array}{l}1,00 \\
0,99 \\
-\end{array}$ \\
\hline
\end{tabular}

NMCE = Nível de met+cis estimado.

$0,677 \%$ de met+cis digestível na ração, respectivamente. Pelo primeiro ponto de interseção da equação quadrática com o platô do LRP, estimou-se o nível de $0,716 \%$ de met+cis digestível equivalente a $0,235 \%$ de met+cis digestível/Mcal de energia metabolizável da ração, correspondente ao consumo de met+cis de 20,77 g/ave para machos e $16,68 \mathrm{~g}$ /ave para fêmeas, durante o período de 28 a 56 dias de idade. O nível de met+cis digestível de $0,716 \%$ na ração correspondeu à relação met+cis: lisina de $71 \%$, exatamente igual à relação recomendada por Atencio et al. (2004) para frangos de corte de 44 a 56 dias e semelhante à relação de $72 \%$, recomendada por Rostagno et al. (2005) para frangos de 21 a 42 dias de idade.

A análise de variância (Tabela 4) evidenciou que os níveis de met+cis da ração afetaram a deposição de gordura das aves, entretanto, os modelos de regressão propostos não se ajustaram adequadamente aos dados, assim, utilizou-se o teste de Duncan para comparar as médias. A dieta contendo $0,875 \%$ de met+cis digestível proporcionou a maior deposição de gordura enquanto aquelas com os demais níveis de met+cis proporcionaram valores semelhantes entre si. Considerando o nível de $0,875 \%$ de met+cis, a relação met+cis:lisina (87\%) foi bastante superior àquela preconizada por Rostagno et al. (2005) para frangos de corte (72\%), o que resultou em desequilíbrio nutricional. Este desequilíbrio pode limitar o crescimento de tecido magro, direcionando energia para os adipócitos, o que explica a maior deposição de gordura pelas aves alimentadas com a ração com $0,875 \%$ de met+cis.

O nível estimado de $0,716 \%$ de met+cis digestível na ração, obtido com base na conversão alimentar, pode ser considerado adequado para melhorar o desempenho de aves ISA Label de ambos os sexos no período de 28 a 56 dias de idade, uma vez que, mesmo naquelas variáveis cujos modelos de regressão não se ajustaram, os melhores resultados foram obtidos com a ração contendo $0,755 \%$ de met+cis, próximo ao nível estimado de $0,716 \%$.
Observou-se efeito de sexo $(\mathrm{P} \leq 0,05)$ para todas as variáveis avaliadas no período de 56 a 84 dias de idade, com exceção do peso relativo das penas e do teor de proteína das penas (Tabela 6). Os níveis de met+cis digestível da ração influenciaram $(\mathrm{P} \leq 0,05)$ o consumo de ração, o consumo de met+cis e a conversão alimentar das aves na fase final, mas não influenciou as demais variáveis avaliadas. A interação entre os fatores estudados para os consumos de ração e de met+cis e a conversão alimentar evidenciou que as respostas aos níveis de met+cis da ração no período de 56 a 84 dias de idade dependem do sexo.

O desdobramento da interação comprovou que os machos reduziram de forma linear o consumo de ração, enquanto nas fêmeas o consumo de ração reduziu de forma quadrática até o nível estimado de $0,578 \%$ de met+cis digestível e aumentou logo em seguida (Tabela 7). Resposta semelhante foi obtida por Silva Jr. et al. (2005), que observaram que o consumo de ração pelas aves reduziu de forma quadrática até o nível estimado de $0,905 \%$ de met+cis total na ração em machos Ross de 22 a 42 dias. Essa redução do consumo de ração com o aumento do nível de met+cis da ração possivelmente esteve relacionada ao melhor balanço de aminoácidos, obtido com a suplementação de DL-metionina nas rações experimentais.

Considerando os dados de conversão alimentar, ficou evidente que os machos responderam até um nível mais elevado de met+cis digestível nas rações em comparação às fêmeas (Tabela 7), ao contrário do comportamento observado no período de 1 a 28 dias de idade. A resposta de conversão alimentar dos machos aos níveis de met+cis da ração foi ajustada adequadamente apenas pelo modelo LRP, no qual foi estimado o nível de $0,756 \%$ de met+cis digestível, correspondendo ao consumo de 30,58 g/ave ou $0,244 \%$ de met+cis digestível/Mcal de metionina da ração. Nas fêmeas, a conversão alimentar melhorou de forma quadrática até o nível estimado de 0,597\% de met+cis 
Tabela 6 - Desempenho de aves ISA Label alimentadas com rações com divesos níveis de met+cis digestível no período de 56 aos 84 dias de idade

\begin{tabular}{|c|c|c|c|c|c|c|c|c|c|c|}
\hline \multirow[t]{2}{*}{ Variável } & \multirow[t]{2}{*}{ Sexo } & \multicolumn{4}{|c|}{ Nível de met+cis digestível } & \multirow[t]{2}{*}{ Geral } & \multirow[t]{2}{*}{$\mathrm{CV}(\%)$} & \multicolumn{3}{|c|}{ Probabilidade de F } \\
\hline & & 0,532 & 0,652 & 0,772 & 0,892 & & & Met + cis & Sexo & $\begin{array}{c}\text { Met }+ \text { cis } \\
\times \text { sexo }\end{array}$ \\
\hline \multirow{3}{*}{ Consumo de ração (g) } & Macho & $4.137,50$ & $4.155,83$ & $4.046,67$ & $4.020,44$ & $4.090,11$ & 2,02 & $\leq 0,05$ & $\leq 0,01$ & $\leq 0,01$ \\
\hline & Fêmea & $3.205,00$ & $3.222,50$ & $3.191,67$ & $3.529,55$ & $3.287,18$ & & & & \\
\hline & Geral & $3.671,25$ & $3.689,17$ & $3.619,17$ & $3.774,99$ & & & & & \\
\hline \multirow{3}{*}{$\begin{array}{l}\text { Consumo de metionina } \\
+ \text { cistina }(\mathrm{g})\end{array}$} & Macho & 19,40 & 24,48 & 28,69 & 33,33 & 26,47 & 2,03 & $\leq 0,01$ & $\leq 0,01$ & $\leq 0,01$ \\
\hline & Fêmea & 15,03 & 18,98 & 22,63 & 29,26 & 21,47 & & & & \\
\hline & Geral & 17,22 & 21,73 & 25,66 & 31,29 & & & & & \\
\hline \multirow{3}{*}{ Ganho de peso $(\mathrm{g})$} & Macho & $1.199,00$ & $1.217,83$ & $1.209,33$ & $1.208,09$ & 1208,56 & 2,84 & NS & $\leq 0,01$ & NS \\
\hline & Fêmea & 807,17 & 826,50 & 822,33 & 799,74 & 813,93 & & & & \\
\hline & Geral & $1.003,08$ & 1022,16 & $1.015,83$ & $1.003,91$ & & & & & \\
\hline \multirow{3}{*}{ Conversão alimentar (g/g) } & Macho & 3,452 & 3,413 & 3,346 & 3,330 & 3,385 & 2,43 & $\leq 0,01$ & $\leq 0,01$ & $\leq 0,01$ \\
\hline & Fêmea & 3,973 & 3,900 & 3,880 & 4,416 & 4,042 & & & & \\
\hline & Geral & 3,713 & 3,657 & 3,613 & 3,873 & & & & & \\
\hline \multirow{3}{*}{ Deposição de proteína (g) } & Macho & 248,39 & 258,95 & 259,59 & 234,73 & 250,41 & 10,30 & NS & $\leq 0,01$ & NS \\
\hline & Fêmea & 173,31 & 179,75 & 193,38 & 184,32 & 182,69 & & & & \\
\hline & Geral & 210,85 & 219,35 & 226,48 & 209,52 & & & & & \\
\hline \multirow{3}{*}{ Deposição de gordura (g) } & Macho & 254,00 & 253,60 & 222,44 & 259,53 & 247,39 & 14,17 & NS & $\leq 0,01$ & NS \\
\hline & Fêmea & 204,77 & 196,73 & 195,17 & 187,59 & 196,06 & & & & \\
\hline & Geral & 229,39 & 225,16 & 208,80 & 223,56 & & & & & \\
\hline \multirow{3}{*}{$\begin{array}{l}\text { Peso relativo } \\
\text { das penas }(\%)\end{array}$} & Macho & 6,09 & 6,19 & 5,64 & 6,16 & 6,02 & 8,91 & NS & NS & NS \\
\hline & Fêmea & 6,41 & 6,22 & 6,45 & 5,97 & 6,26 & & & & \\
\hline & Geral & 6,25 & 6,20 & 6,05 & 6,06 & & & & & \\
\hline \multirow{3}{*}{$\begin{array}{l}\text { Teor de proteína } \\
\text { das penas }(\%)\end{array}$} & Macho & 85,39 & 86,40 & 86,71 & 85,33 & 85,96 & 1,24 & NS & NS & NS \\
\hline & Fêmea & 86,21 & 86,88 & 86,63 & 86,75 & 86,62 & & & & \\
\hline & Geral & 85,80 & 86,64 & 86,67 & 86,04 & & & & & \\
\hline
\end{tabular}

$\mathrm{CV}=$ coeficiente de variação; $\mathrm{NS}=$ não-significativo $(\mathrm{P}>0,05)$.

Tabela 7 - Equações ajustadas para o consumo de ração, consumo de met+cis e conversão alimentar em cada nível de met+cis digestível da ração, coeficientes de determinação $\left(\mathrm{R}^{2}\right)$ e níveis de met+cis estimados (NMCE) com diferentes modelos

\begin{tabular}{|c|c|c|c|}
\hline Modelo & Variável/Equação & NMCE $(\%)$ & $\mathrm{R}^{2}$ \\
\hline Linear & $\begin{array}{c}\text { Consumo de ração }(\mathrm{g})-\text { Machos } \\
\mathrm{CR}=4339,08-383,626 \mathrm{MC} \\
\text { Consumo de ração }(\mathrm{g})-\text { Fêmeas }\end{array}$ & - & 0,80 \\
\hline Quadrático & $\mathrm{CR}=5019,95-6434,04 \mathrm{MC}+5562,18 \mathrm{MC}^{2}$ & 0,578 & 0,89 \\
\hline Linear & $\begin{array}{l}\text { Consumo de met+cis digestível }(\mathrm{g})-\text { Machos } \\
\text { CMet }=1,60462+38,3222 \mathrm{MC} \\
\text { Consumo de met+cis digestível }(\mathrm{g})-\text { Fêmeas }\end{array}$ & - & 0,99 \\
\hline Linear & CMet $=-3,58371+38,6116 \mathrm{MC}$ & - & 0,98 \\
\hline $\begin{array}{l}\text { LRP } \\
\text { Linear } \\
\text { Quadrático }\end{array}$ & $\begin{array}{c}\text { Conversão alimentar }(\mathrm{g} / \mathrm{g})-\text { Machos } \\
\mathrm{CA}=3,66551-0,443899 \mathrm{MC}(\mathrm{p} / \mathrm{MC}<0,756 \%) \\
\mathrm{CA}=3,6211-0,363024 \mathrm{MC} \\
\text { Conversão alimentar }(\mathrm{g} / \mathrm{g})-\text { Fêmeas } \\
\mathrm{CA}=7,58984-12,6098 \mathrm{MC}+10,5562 \mathrm{MC} 2\end{array}$ & $\begin{array}{c}0,756 \\
-\end{array}$ & $\begin{array}{l}0,98 \\
0,96\end{array}$ \\
\hline
\end{tabular}

digestível na ração, correspondente ao consumo de 19,46 g/ave ou 0,193\% de met+cis digestível/Mcal de EM da ração, durante o período de 56 a 84 dias. Com base nesses resultados, estimaram-se as relações met+cis:lisina de $99 \%$ para os machos e $79 \%$ para as fêmeas. A relação de $99 \%$ estimada para os machos foi bastante superior às relações recomendada por Rostagno et al. (2005), 72\%, e por Silva Jr. et al. (2005), 76\%, para frangos de ambos os sexos dos 43 aos 56 dias e para frangos machos dos 22 aos 42 dias, respectivamente. Da mesma forma, a relação de $79 \%$ estimada para as fêmeas ISA Label de 56 a 84 dias foi superior às recomendações de Rostagno et al. (2005) 
(72\%), entretanto, foi levemente inferior à relação de $82 \%$ recomendada por Silva Jr. et al. (2006) para fêmeas Ross de 22 a 42 dias de idade.

Os rendimentos de carcaça, peito desossado, peito com osso, coxa, sobrecoxa e a porcentagem de gordura abdominal das aves não foram influenciados $(\mathrm{P}>0,05)$ pelos níveis de met+cis digestível da ração (Tabela 8). Esses resultados estão de acordo com aqueles encontrados por Rodrigueiro et al. (2000), que também não observaram efeito dos níveis de met+cis sobre os rendimentos de carcaça, partes nobres e gordura abdominal de frangos de corte aos 56 dias de idade. Entretanto, divergem dos resultados encon- trados por Atencio et al. (2004), que observaram melhora no rendimento de peito e de carne de peito em frangos Avian Farm dos 44 aos 56 dias de idade.

As fêmeas apresentaram valores superiores de peito desossado, peito com osso e gordura abdominal e inferiores de coxa em comparação aos machos, aos 84 dias de idade. Essa diferença entre machos e fêmeas evidenciou que as fêmeas, apesar de depositarem maior quantidade de gordura abdominal, tiveram maior rendimento de carnes nobres, como a do peito, conforme observado em estudos realizados por Santos et al. (2005) e Nascimento (2007) com aves ISA Label.

Tabela 8 - Médias de rendimento de carcaça, peito desossado e com osso, coxa, sobrecoxa e porcentagem de gordura abdominal, de aves ISA Label aos 84 dias de idade

\begin{tabular}{|c|c|c|c|c|c|c|c|c|c|c|}
\hline \multirow[t]{2}{*}{ Variável } & \multirow[t]{2}{*}{ Sexo } & \multicolumn{4}{|c|}{ Nível de met+cis digestível } & \multirow[t]{2}{*}{ Geral } & \multirow[t]{2}{*}{$\mathrm{CV}(\%)$} & \multicolumn{3}{|c|}{ Probabilidade de F } \\
\hline & & 0,532 & 0,652 & 0,772 & 0,892 & & & Met+cis & Sexo & $\begin{array}{c}\text { Met+cis } \\
\times \text { sexo }\end{array}$ \\
\hline \multirow[t]{3}{*}{ Rendimento de carcaça (\%) } & Macho & 77,81 & 76,42 & 79,18 & 77,17 & 77,64 & 2,30 & NS & NS & NS \\
\hline & Fêmea & 76,84 & 75,78 & 77,12 & 76,60 & 76,59 & & & & \\
\hline & Geral & 77,33 & 76,10 & 78,15 & 76,88 & & & & & \\
\hline \multirow[t]{3}{*}{ Peito desossado $(\%)$} & Macho & 18,93 & 19,15 & 18,40 & 18,53 & 18,75 & 4,68 & NS & $\leq 0,01$ & NS \\
\hline & Fêmea & 19,98 & 20,16 & 21,67 & 20,78 & 20,65 & & & & \\
\hline & Geral & 19,45 & 19,66 & 20,03 & 19,66 & & & & & \\
\hline \multirow[t]{3}{*}{ Peito com osso $(\%)$} & Macho & 25,81 & 26,37 & 25,14 & 25,28 & 25,65 & 3,21 & NS & $\leq 0,01$ & NS \\
\hline & Fêmea & 26,52 & 27,54 & 28,42 & 27,63 & 27,53 & & & & \\
\hline & Geral & 26,17 & 26,96 & 26,78 & 26,46 & & & & & \\
\hline \multirow[t]{3}{*}{ Coxa $(\%)$} & Macho & 13,62 & 13,89 & 13,88 & 14,60 & 14,00 & 4,20 & NS & $\leq 0,01$ & NS \\
\hline & Fêmea & 13,44 & 13,25 & 13,50 & 12,92 & 13,28 & & & & \\
\hline & Geral & 13,53 & 13,57 & 13,69 & 13,76 & & & & & \\
\hline \multirow[t]{3}{*}{ Sobrecoxa $(\%)$} & Macho & 15,80 & 15,92 & 15,77 & 15,78 & 15,82 & 4,24 & NS & NS & NS \\
\hline & Fêmea & 15,80 & 16,29 & 15,75 & 16,05 & 15,97 & & & & \\
\hline & Geral & 15,80 & 16,10 & 15,76 & 15,92 & & & & & \\
\hline \multirow[t]{3}{*}{ Gordura abdominal (\%) } & Macho & 3,69 & 3,92 & 3,84 & 3,14 & 3,65 & 15,68 & NS & $\leq 0,01$ & NS \\
\hline & Fêmea & 5,32 & 5,96 & 4,79 & 5,64 & 5,43 & & & & \\
\hline & Geral & 4,51 & 4,94 & 4,32 & 4,39 & & & & & \\
\hline
\end{tabular}

$\mathrm{CV}=$ coeficiente de variação; $\mathrm{NS}=$ não-significativo $(\mathrm{P}>0,05)$.

\section{Conclusões}

Recomenda-se 0,765 e $0,803 \%$ de met+cis digestível na ração para aves ISA Label no período de 1 a 28 dias de idade ou 0,252 e $0,268 \%$ de met+cis por Mcal de energia metabolizável da ração para machos e fêmeas, respectivamente. Para o período de 28 a 56 dias de idade, recomenda-se $0,716 \%$ de met+cis digestível na ração, independentemente do sexo, ou 0,235\% de met+cis por Mcal de energia metabolizável da ração. No período de 56 a 84 dias de idade, recomendam-se níveis de 0,756 e $0,597 \%$ de met+cis digestível ou 0,244 e $0,193 \%$ de met+cis por Mcal de energia metabolizável da ração, para machos e fêmeas, respectivamente.

\section{Literatura Citada}

ALBINO, L.F.T.; SILVA, S.H.M.; VARGAS JR., J.G. Níveis de metionina + cistina para frangos de corte de 1 a 21 e 22 a 42 dias de idade. Revista Brasileira de Zootecnia, v.28, n.3, p.519-525, 1999.

ATENCIO, A.; ALBINO, L.F.T.; ROSTAGNO, H.S. et al. Exigências de metionina + cistina para frangos de corte machos em diferentes fases de criação. Revista Brasileira de Zootecnia, v.33, n.5, p.1152-1166, 2004.

BAKER, D.H.; BATAL, A.B.; PARR, T.M. et al. Ideal ratio (relative to lysine) of tryptophan, threonine, isoleucine and valine for chicks during the second and third weeks posthatch. Poultry Science, v.81, p.485-494, 2002.

BOOMGARDT, J.; BAKER, D.H. Effect of dietary energy concentration on sulfur amino acid requirement and body composition of young chicks. Journal of Animal Science, v.36, p.307-311, 1973 . 
GOUS, R.M.; MORAN, E.T.; STILBORN, H.R. et al. Evaluation of the parameters needed to describe the overall growth, the chemical growth, and the growth of feathers and breast muscles of broilers. Poultry Science, v.78, p.812-821, 1999.

HAN, Y.; BAKER, D.H. Ideal amino acid profile for chicks during the first three weeks posthatching. Poultry Science, v.73, p.1441-1447, 1994.

HRUBY, M. The amino acid maintenance and growth requirements of male broilers. 1998. 144f. Thesis (Ph.D. in Animal Science) - University of Minnesota, Minnesota, 1998.

JENSEN, L.S. Concepts of amino acid and protein nutrition in poultry. In: COLÉGIO BRASILEIRO DE NUTRIÇÃO ANIMAL, 1990, Campinas. Anais... Campinas: Colégio Brasileiro de Nutrição Animal, 1990. p.99-108.

KALINOWSKI, A.; MORAN JR., E.T.; WYATT, C. Methionine and cystine requirements of slow- and fast-feathering male broilers from zero to three weeks of age. Poultry Science, v.82, p.1423-1427, 2003a.

KALINOWSKI, A.; MORAN JR., E.T.; WYATT, C. Methionine and cystine requirements of slow- and fast-feathering male broilers from three to six weeks of age. Poultry Science, v.82, p.1428-1437, 2003b.

KESSLER, A.M.; SNIZEK JR., P.N.; BRUGALLI, I. Manipulação da quantidade de gordura na carcaça de frangos. In: SIMPÓSIO INTERNACIONAL SOBRE DESENVOLVIMENTO DE CARCAÇA DE FRANGOS: OSSO, MÚSCULO, GORDURA E PENA, CONFERÊNCIA APINCO DE CIÊNCIA E TECNOLOGIAS AVÍCOLAS, 2000, Campinas. Anais... Campinas: 2000, p.107-133.

KYRIAZAKIS, I.; DOTAS, D.; EMMANS, G.C. The effects of breed on the relationship between feed composition and the efficiency of protein utilization in pigs. British Journal of Nutrition, v.71, p.849-859, 1994.

NASCIMENTO, D.C.N. Exigências de lisina e de metionina + cistina digestível para aves de corte da linhagem ISA Label em sistema semi-confinado. 2007. 76f. Dissertação (Mestrado em Zootecnia) - Faculdade de Ciências Agrárias e Veterinárias, Universidade Estadual Paulista, Jaboticabal, 2007.

NATIONAL RESEARCH COUNCIL - NRC. Nutrient requirements of poultry. 9.ed. Washington, D.C.: National Academy of Science, 1994. 154p.
OLIVEIRA NETO, A.R.; OLIVEIRA, R.F.M.; DONZELE, J.L. et al. Níveis de metionina + cistina para pintos de corte mantidos em ambiente termoneutro. Revista Brasileira de Zootecnia, v.34, n.6, p.1956-1962, 2005.

PESTI, G.M.; LECLERCQ, B.; CHAGNEAU, A.M. et al. Effects of the naked neck (na) gene on the sulfur-containing amino acid requirements of broilers. Poultry Science, v.75, p.375-380, 1996.

RADEMACHER, M. Por qué es importante considerar la proporción "minima" de metionina sobre metionina + cistina total en las dietas de cerdos? Amino News, v.1, n.1, p.7-10, 2001.

RODRIGUEIRO, R.J.B.; ALBINO, L.F.T.; ROSTAGNO, H.S. et al. Exigência de metionina + cistina para frangos de corte na fase de crescimento e acabamento. Revista Brasileira de Zootecnia, v.29, n.2, p.507-517, 2000.

ROSTAGNO, H.S.; ALBINO, L.F.T.; DONZELE, J.L. et al. Tabelas brasileiras para aves e suínos (composição de alimentos e exigências nutricionais). 2.ed. Viçosa, MG: Editora UFV, 2005. 186p.

SAKOMURA, N.K.; ROSTAGNO, H.S. Métodos de pesquisa em nutrição de monogástricos. Jaboticabal: Funep, 2007. 283p.

SANTOS, A.L.; SAKOMURA, N.K.; FREITAS, E.R. et al. Estudo do crescimento, desempenho, rendimento de carcaça e qualidade de carne de três linhagens de frango de corte. Revista Brasileira de Zootecnia, v.34, n.5, p.1589-1598, 2005.

SHUTTE, J.B.; PACK, M. Sulfur amino acid requirement of broiler chicks from fourteen to thirty-eight days of age. 1. Performance and carcass yield. Poultry Science, v.74, p. 480-487, 1995.

SILVA JR., R.G.C.; LANA, G.R.Q.; RABELLO, C.B. et al. Exigências de metionina + cistina para frangos de corte machos de 1 a 21 e de 22 a 42 dias de idade, em clima tropical. Revista Brasileira de Zootecnia, v.34, n.6, p2399-2407, 2005 (supl.).

SILVA JR., R.G.C.; LANA, G.R.Q.; RABELLO, C.B. et al. Exigências de metionina + cistina para frangos de corte fêmeas de 1 a 21 e de 22 a 42 dias de idade criados em região de clima tropical. Revista Brasileira de Zootecnia, v.35, n.2, p.497-503, 2006.

SILVA, D.J.; QUEIROZ, A.C. Análise de alimentos: métodos químicos e biológicos. 3.ed. Viçosa, MG: Editora UFV, 2002. 235p.

UNIVERSIDADE FEDERAL DE VIÇOSA - UFV. Sistema de análises estatísticas e genéticas - SAEG. Versão 9.0. Viçosa, MG, 2001. 301p. 